\title{
CRESCIMENTO E QUALIDADE DE MUDAS DE Senna macranthera (COLLAD.) IRWIN ET BARN. EM RESPOSTA À CALAGEM ${ }^{1}$
}

\author{
Paulo Henrique de Souza², Haroldo Nogueira de Paiva ${ }^{3}$, Júlio César Lima Neves ${ }^{4}$, José Mauro \\ Gomes $^{3}$ e Lissandra Silva Marques ${ }^{5}$
}

\begin{abstract}
RESUMO - Este trabalho foi desenvolvido com o objetivo de verificar a influência da saturação por bases do substrato no crescimento inicial e qualidade de mudas de Senna macranthera (fedegoso). O delineamento utilizado foi em blocos ao acaso com quatro repetições por tratamento. Como substrato foram empregados três diferentes solos, sendo para cada um deles a saturação por bases original elevada para os seguintes valores: Argissolo Vermelho-Amarelo 50, 60 e 70\%, Latossolo Vermelho-Amarelo distrófico 30, 50 e 70\% e Latossolo Vermelho-Amarelo álico 25, 45 e 65\%. Foram avaliados os parâmetros morfológicos das mudas, suas relações e o índice de qualidade de Dickson. As mudas de fedegoso não apresentaram diferença significativa para nenhuma das características avaliadas no Argissolo Vermelho-Amarelo. Já no Latossolo Vermelho-Amarelo distrófico e no Latossolo Vermelho-Amarelo álico houve diferença significativa para todas as características avaliadas, exceto para a altura da parte aérea no primeiro e para o peso de matéria seca da parte aérea no segundo solo. As saturações por bases que forneceram as melhores mudas foram de 60\% para Argissolo Vermelho-Amarelo, 70\% para o Latossolo Vermelho-Amarelo distrófico e de 65\% para Latossolo Vermelho-Amarelo álico.
\end{abstract}

Palavras-chave: Saturação por bases, Qualidade de mudas e Fedegoso.

\section{GROWTH AND SEEDLING QUALITY OF Senna macranthera (COLLAD.) IRWIN ET BARN. IN RESPONSE TO CALAGEM}

\begin{abstract}
The present work was developed with the objective of verifying the influence on the base saturation of the substratum in the initial growth and seedling quality of the Senna macranthera (fedegoso) seeds. A complete randomized design in blocs with four repetitions per treatment was utilized. Three different soils were used as a substratum, and for each, the original saturation was raised to the following values: redyellow claysoil 50, 60, and 70\%; red-yellow dystrophic latosoil 30, 50, and 70\%; red-yellow alic latosoil 25,45 , e $65 \%$. The seedlings morphological parameters, their relationships and the Dickson's quality index were evaluated. The fedegoso seedlings did not present any significant difference to any of the characteristics evaluated in the argisoil, with the largest average values in the $70 \%$ base saturation. In the red-yellow dystrophic latosoil and the alic latosol there was a significant difference in all of the evaluated characteristics, except for the height of the aerial parts in the former soil and for the weight of the dry material of the aerial part of the latter one, with the $65 \%$ base saturation providing the best seedling of the species.
\end{abstract}

Keywords: Base saturation, Seedling quality and Fedegoso.

\section{INTRODUÇÃo}

Geralmente, os solos ácidos apresentam teores de alumínio que podem ser fitotóxicos e, ou, baixos teores de cálcio e magnésio trocáveis. Essas características, que são desfavoráveis ao desenvolvimento da maioria das espécies, podem ser corrigidas pela calagem (AMARAL et al., 2000), que é uma das práticas menos dispendiosas e mais efetivas na correção da acidez do solo (FAGEIRA, 2001). Essa correção da acidez afeta o crescimento e qualidade de mudas, por promover alteração do pH e, assim, influenciar na disponibilização de nutrientes no solo e, consequentemente, na sua absorção pelas plantas (BARBOSA et al., 1995).

\footnotetext{
${ }^{1}$ Recebido em 15.08.2007 e aceito para publicação em 14.10.2009.

${ }^{2}$ Universidade Presidente Antônio Carlos/Aimorés, Brasil. E-mail: <phsufv@yahoo.com.br>.

${ }^{3}$ Departamento de Engenharia Florestal, Universidade Federal de Viçosa - Vicosa, MG - Brasil. E-mail: <hnpaiva@ufv.br>, <jmgomes@ufv.br>e <lissandramarques@yahoo.com.br>.

${ }^{4}$ Departamento de Solos, Universidade Federal de Viçosa, UFV, Brasil. E-mail: <julio_n2003@yahoo.com.br>.

${ }^{5}$ Ambiente Brasil. E-mail: <lissandramarques@yahoo.com.br>.
} 
Correções de solo, seguidas de adubações com alta carga de fertilizantes, têm sido práticas comuns visando ao aumento da produtividade das culturas, necessitando conhecer melhor a dinâmica dos nutrientes no solo e na planta, as exigências nutricionais da cultura e os fatores que afetam o equilíbrio dentro do complexo solo-planta (FERNANDES e CARVALHO, 2001).

Segundo Fernández et al. (1996), grande parte das informações nutricionais durante a fase de mudas podem ser extrapoladas para a fase de crescimento em campo, e a falta de conhecimento dessas informações leva à necessidade de realização de ensaios como o aqui proposto.

Senna macranthera é uma espécie semidecídua ou decídua durante o inverno, heliófita, pioneira, indiferente às características físicas do solo, e muito frequente em formações secundárias de regiões de altitude. Produz anualmente grande quantidade de sementes viáveis e floresce de maneira exuberante durante vários meses do ano (LORENZI, 1992).

Na região da Zona da Mata de Minas Gerais, devido ao seu potencial paisagístico e crescimento rápido, essa espécie tem sido utilizada na arborização de pastagens, levando à necessidade de estudos sobre o seu comportamento nos tipos de solos presentes na região. Diante disso, este trabalho teve como objetivo estudar a influência da saturação por bases do substrato no crescimento inicial e na qualidade de mudas de fedegoso Senna macranthera, quando produzidas em três diferentes solos, Argissolo Vermelho-Amarelo, Latossolo Vermelho-Amarelo distrófico e Latossolo Vermelho-Amarelo álico, comuns na região da Zona da Mata de Minas Gerais.

\section{MATERIAL E MÉTODOS}

O experimento foi conduzido em casa de vegetação no Viveiro de Pesquisas do Departamento de Engenharia Florestal da Universidade Federal de Viçosa, situado nas coordenadas geográficas $-20^{\circ} 45^{\prime} 25,0^{\prime \prime}$ de latitude sul e $-42^{\circ} 51^{\prime} 11,0^{\prime \prime}$ longitude oeste, a $658 \mathrm{~m}$ de altitude e compreendeu o período de novembro de 2004 a junho de 2005.

A espécie utilizada foi Senna macranthera (Collad.) Irwin et Barn., sendo as sementes adquiridas no Setor de Silvicultura do Departamento de Engenharia Florestal da UFV.

R. Árvore, Viçosa-MG, v.34, n.2, p.233-240, 2010

\section{R. Árvore, Viçosa-MG, v.34, n.2, p.233-240, 2010}

Como substrato foram utilizados três diferentes solos, um Argissolo Vermelho-Amarelo, um Latossolo Vermelho-Amarelo distrófico e um Latossolo VermelhoAmarelo álico, todos provenientes de áreas próximas à Viçosa, retirados na camada entre 0,2 m e 1,0 m de profundidade, cujas características químicas podem ser observadas no Tabela 1. Esses solos foram peneirados em malha de $5 \mathrm{~mm}$ e secos ao ar. Posteriormente, foram pesadas porções de $2,1 \mathrm{~kg}$ de solo e colocadas em sacos plásticos sobre a bancada da casa de vegetação, onde permaneceram incubados por um período de 30 dias com a umidade mantida próximo de $60 \%$ da capacidade de campo.

Com a finalidade de estabelecer diferentes valores de saturação por bases, foram utilizadas proporções variadas de $\mathrm{CaCO}_{3}$ e $\mathrm{MgCO}_{3}$ na relação estequiométrica 4:1 (Tabela 2), segundo o método da saturação por bases, utilizando-se para cálculo a seguinte fórmula:

$$
\mathrm{NC}(\mathrm{t} / \mathrm{ha})=\left(\mathrm{V}_{2}-\mathrm{V}_{1}\right) \mathrm{T} / 100
$$

em que:

$\mathrm{NC}=$ necessidade de calagem em toneladas por hectare;

$\mathrm{V}_{1}$ = porcentagem de saturação por bases original do solo, conforme análise;

$\mathrm{V}_{2}=$ porcentagem de saturação por bases desejada; e

$\mathrm{T}=$ capacidade de troca catiônica, a pH 7,0.

A adubação de base foi efetuada logo após o período de incubação e dois dias antes da semeadura, em solução, e consistiu na aplicação de $300 \mathrm{mg} / \mathrm{dm}^{3}$ de $\mathrm{P}, 100 \mathrm{mg} / \mathrm{dm}^{3} \mathrm{de} \mathrm{K}, 40 \mathrm{mg} / \mathrm{dm}^{3}$ de S e $100 \mathrm{mg} / \mathrm{dm}^{3}$ de $\mathrm{N}$, usando-se como fontes o $\mathrm{NaH}_{2} \mathrm{PO}_{4} \cdot \mathrm{H}_{2} \mathrm{O}, \mathrm{KH}_{2} \mathrm{PO}_{4}$, $\mathrm{K}_{2} \mathrm{SO}_{4}$ e $\mathrm{NH}_{4} \mathrm{NO}_{3}$, respectivamente, conforme sugerido por Passos (1994). Foi aplicada também, como adubação de base solução de micronutrientes nas seguintes doses: 0,81 mg/dm ${ }^{3}$ de B, 1,33 mg/dm ${ }^{3}$ de Cu, 0,15 mg/dm ${ }^{3}$ de Mo, 3,66 mg/dm ${ }^{3}$ de Mn e 4,0 mg/dm ${ }^{3}$ de $\mathrm{Zn}$, com as seguintes fontes, respectivamente: $\mathrm{H}_{3} \mathrm{BO}_{3}, \mathrm{CuSO}_{4} \cdot 5 \mathrm{H}_{2} \mathrm{O}$, $\left(\mathrm{NH}_{4}\right)_{6} \mathrm{Mo}_{7} \mathrm{O}_{24} \cdot 4 \mathrm{H}_{2} \mathrm{O}, \mathrm{MnCl}_{2} \cdot \mathrm{H}_{2} \mathrm{O}$ e $\mathrm{ZnSO}_{4} \cdot 7 \mathrm{H}_{2} \mathrm{O}$, de acordo com Alvarez (1974).

Como adubação de cobertura foram aplicados $20 \mathrm{mg} / \mathrm{dm}^{3}$ de $\mathrm{N}$ aos 30 e 60 dias após a germinação das sementes, usando como fonte $\mathrm{NH}_{4} \mathrm{NO}_{3}$. Aos 90 dias, além do $\mathrm{N}$, foram aplicados também 55,8 mg/ $\mathrm{dm}^{3}$ de $\mathrm{K}$, utilizando-se como fonte o $\mathrm{KNO}_{3}$, de acordo com Garcia (1986). 
Tabela 1 - Análise química das amostras de solo utilizadas no experimento.

Table 1 - Chemical Characteristics of the soil samples utilized in the experiment.

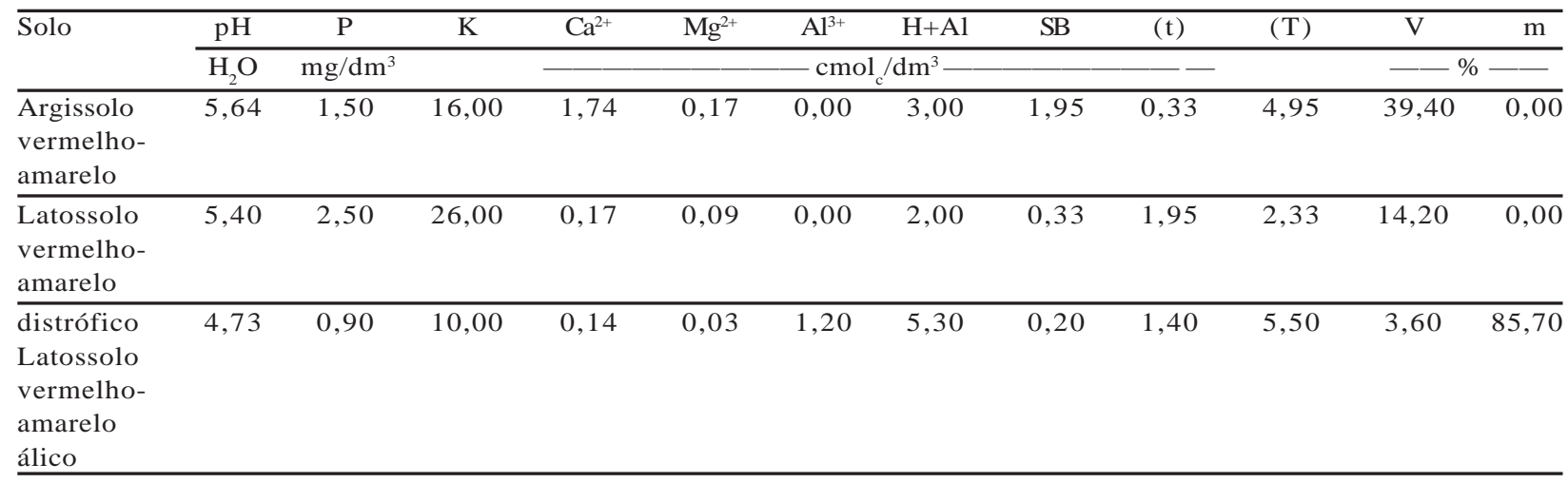

pH em água - Relação 1: 2,5; P e K - Extrator Mehlich 1; $\mathrm{Ca}^{2+}, \mathrm{Mg}^{2+}$ e $\mathrm{Al}^{3+}-$ Extrator: $\mathrm{KCl} 1$ mol/L; $\mathrm{H}+\mathrm{Al}-\mathrm{Extrator}$ Acetato de Cálcio 0,5 mol/L - pH 7,0; SB = Soma de Bases Trocáveis; $(\mathrm{t})=$ Capacidade de troca catiônica efetiva; $(\mathrm{T})=$ Capacidade de troca catiônica a pH 7,0; V = índice de saturação por bases; e m = índice de saturação por alumínio.

Tabela 2 - Valores de saturação por bases originais das amostras de solo e tratamentos aplicados. Table 2 - Original base saturation values of the soil samples and treatments applied.

\begin{tabular}{lcccc}
\hline Solo & Original & Tratamento 1 & Tratamento 2 & Tratamento 3 \\
\cline { 2 - 5 } & \multicolumn{3}{c}{ V (\%) } \\
\hline Argissolo vermelho-amarelo & 39,40 & 50,00 & 60,00 & 70,00 \\
Latossolo vermelho-amarelo distrófico & 14,20 & 30,00 & 50,00 & 70,00 \\
Latossolo vermelho-amarelo álico & 3,60 & 25,00 & 45,00 & 65,00 \\
\hline
\end{tabular}

Para a produção das mudas, cada vaso de polietileno rígido de $0,17 \mathrm{~m}$ de altura por $0,15 \mathrm{~m}$ de diâmetro e capacidade de $2,1 \mathrm{dm}^{3}$ de solo recebeu 10 sementes. Aos 15 dias após a emergência das plântulas foi efetuado um primeiro raleio, deixando-se duas plantas por vaso, e aos 30 dias um segundo raleio foi realizado, deixandose apenas uma planta por vaso.

Aos 120 dias após a semeadura foram medidos a altura (H) e o diâmetro do coleto (DC) de todas as plantas. $\mathrm{H}$ foi medida com uma régua de precisão de 0,1 cm, e para a medição do DC utilizou-se um paquímetro digital com precisão de $0,01 \mathrm{~mm}$. As plantas foram, então, divididas em parte aérea e em raízes, lavadas em água destilada, colocadas em sacos de papel pardo e postas a secar em estufa a $65^{\circ} \mathrm{C}$ por 72 horas com circulação de ar forçada. Após a secagem, o material foi pesado em balança analítica com precisão de 0,01 g, para determinação das características: peso de matéria seca da parte aérea (PMSPA) e peso de matéria seca das raízes (PMSR).
Na determinação da qualidade das mudas foram avaliados, além das características mencionadas anteriormente, o peso de matéria seca total (PMST), as relações entre a altura da parte aérea e o diâmetro do coleto (H/DC), a altura da parte aérea e o peso de matéria seca da parte aérea (H/PMSPA), o peso de matéria seca da parte aérea e o peso de matéria seca das raízes (PMSPA/PMSR) e o índice de qualidade de Dickson (IQD), segundo metodologia utilizada por Gomes (2001), em que IQD = PMST/(H/DC + PMSPA/PMSR $)$.

O experimento foi disposto em blocos ao acaso com quatro repetições, sendo cada vaso considerado uma unidade experimental. Os dados foram comparados por meio de análises de variância e regressão. O modelo utilizado na análise de variância foi o teste " $F$ " a 5\% de probabilidade. A escolha do melhor modelo de regressão foi feita com base no coeficiente de determinação a 5\% de probabilidade, a partir do teste "t", de Student, utilizando-se o programa SAS (Sistema para Análises Estatísticas).

R. Árvore, Viçosa-MG, v.34, n.2, p.233-240, 2010 


\section{RESULTADOS E DISCUSSÃO}

As saturações por bases do substrato que forneceram a maior e a menor média para todas as características avaliadas no Argissolo VermelhoAmarelo, inclusive para o PMST, foram, respectivamente, $60 \%$ e $70 \%$. No Latossolo Vermelho-Amarelo álico, a maior saturação por bases testada (65\%) foi a que forneceu as maiores médias para todas as características avaliadas. As mudas de fedegoso produzidas nos três solos apresentaram um valor mínimo para o DC igual a 3,66 mm (Tabela 3). Valores semelhantes foram encontrados por Bernardino et al. (2005) em mudas de angico-vermelho, que foram consideradas adequadas para o plantio no campo.

Analisando a relação entre as características, observou-se que no Latossolo Vermelho-Amarelo distrófico a não utilização do corretivo, ou seja, quando as mudas foram produzidas na saturação por bases original do solo (14,2\%), resultou no menor valor do IQD (Tabela 4). Já os maiores valores dessa característica

Tabela 3 - Médias de altura (H), diâmetro do coleto (DC), peso de matéria seca da parte aérea (PMSPA), peso de matéria seca das raízes (PMSR) e peso de matéria seca total (PMST) das mudas de fedegoso em resposta à saturação por bases do substrato, aos 120 dias após a semeadura.

Table 3 - Means of height (H), stem diameter (DC), dry matter of the aerial part (PMSPA), root dry matter (PMSR), and total dry matter weight (PMST) of the fedegoso seedlings in response to the base saturation of the substratum, at 120 days after sowing.

\begin{tabular}{|c|c|c|c|c|c|c|}
\hline Solo & Saturação(\%) & $\mathrm{H}(\mathrm{cm})$ & $\mathrm{DC}(\mathrm{mm})$ & PMSPA(g) & PMSR(g) & $\operatorname{PMST}(\mathrm{g})$ \\
\hline \multirow[t]{4}{*}{ Argissolo vermelho-amarelo } & 39,4 & 28,38 & 8,12 & 8,51 & 7,51 & 16,02 \\
\hline & 50 & 27,38 & 8,34 & 7,86 & 8,72 & 16,58 \\
\hline & 60 & 30,75 & 8,74 & 8,93 & 9,13 & 18,06 \\
\hline & 70 & 19,63 & 6,68 & 6,35 & 6,44 & 12,79 \\
\hline \multirow[t]{4}{*}{ Latossolo vermelho-amarelo distrófico } & 14,2 & 13,63 & 3,66 & 1,52 & 0,92 & 2,43 \\
\hline & 30 & 18,00 & 6,01 & 4,03 & 2,82 & 6,85 \\
\hline & 50 & 12,88 & 5,71 & 3,75 & 3,24 & 6,99 \\
\hline & 70 & 14,88 & 6,45 & 5,19 & 4,33 & 9,52 \\
\hline \multirow[t]{4}{*}{ Latossolo vermelho-amarelo álico } & 3,6 & 15,38 & 4,52 & 2,54 & 1,03 & 3,57 \\
\hline & 25 & 22,93 & 7,92 & 6,54 & 7,10 & 13,64 \\
\hline & 45 & 14,50 & 5,94 & 7,73 & 4,64 & 12,37 \\
\hline & 65 & 29,25 & 8,44 & 10,40 & 7,85 & 18,25 \\
\hline
\end{tabular}

Tabela 4-Médias das relações entre as características altura e diâmetro do coleto (H/DC), altura e peso de matéria seca da parte aérea (H/PMSPA), peso de matéria seca da parte aérea e peso de matéria seca das raízes (PMSPA/PMSR) e do índice de qualidade de Dickson das mudas de fedegoso em resposta à saturação por bases do substrato, aos 120 dias após a semeadura.

Table 4 - Means of the ratio between the characteristics of the height and stem diameter (H/DC), height and dry matter of the aerial part (H/PMSPA), dry matter weight of the aerial part and dry matter weight of the roots (PMSPA) PMSR) and of the Dickson's quality index of the fedegoso seedlings in response to the base saturation of the substratum at 120 days after sowing.

\begin{tabular}{lccccc}
\hline Solo & Saturação $(\%)$ & H/DC & H/PMSPA & PMSPA/PMSR & IQD \\
\hline Argissolo vermelho-amarelo & 39,4 & 3,50 & 3,33 & 1,13 & 3,46 \\
& 50 & 3,28 & 3,48 & 0,90 & 3,96 \\
& 60 & 3,52 & 3,44 & 0,98 & 4,02 \\
& 70 & 2,94 & 3,09 & 0,99 & 3,26 \\
\hline Latossolo vermelho-amarelo distrófico & 14,2 & 3,72 & 8,97 & 1,65 & 0,45 \\
& 30 & 3,00 & 4,47 & 1,43 & 1,55 \\
& 50 & 2,26 & 3,43 & 1,16 & 2,05 \\
Latossolo vermelho-amarelo álico & 70 & 2,31 & 2,87 & 1,20 & 2,72 \\
& 3,6 & 3,40 & 6,06 & 2,47 & 0,61 \\
& 25 & 2,90 & 3,51 & 0,92 & 3,57 \\
& 45 & 2,44 & 1,88 & 1,67 & 3,01 \\
& 65 & 3,47 & 2,81 & 1,32 & 3,81 \\
\hline
\end{tabular}

R. Árvore, Viçosa-MG, v.34, n.2, p.233-240, 2010 
no Latossolo Vermelho-Amarelo distrófico e no Latossolo Vermelho-Amarelo álico foram alcançados, respectivamente, nas saturações por bases de 70 e 65\% (Tabela 4). Gomes (2001), citando trabalhos de outros pesquisadores, afirmou que, quanto maior o valor do IQD e menor o valor da relação H/PMSPA e da relação PMSPA/PMSR, melhor será a qualidade da muda produzida.

Os valores encontrados para o IQD ficaram acima dos recomendados na literatura para mudas de Pseudotsuga menziesii e Picea abies. Para mudas dessa espécie, ficou estabelecido o valor mínimo de 0,20 como bom indicador da qualidade de mudas (HUNT, 1990 citado por GOMES, 2001). Esse fato está associado aos maiores valores obtidos para a massa seca das raízes das mudas de fedegoso, diminuindo o valor da relação entre o PMSPA/PMSR.

As mudas de fedegoso não apresentaram diferença significativa para nenhuma das características avaliadas em função da elevação da saturação por bases quando o substrato utilizado foi o Argissolo VermelhoAmarelo (Tabelas 5 e 6). Tal fato pode estar relacionado aos teores iniciais de $\mathrm{Ca}^{2+}\left(1,74 \mathrm{cmol}_{\mathrm{c}} / \mathrm{dm}^{3}\right)$ e $\mathrm{Mg}^{2+}$ $\left(0,17 \mathrm{cmol}_{c} / \mathrm{dm}^{3}\right)$ presentes no substrato e que já seriam suficientes para suprir as necessidades do fedegoso, pelo menos durante a fase de muda.
Resultados semelhantes foram observados por Bernardino et al. (2005) em angico-vermelho no mesmo tipo de solo, e também por Gomes et al. (2004) em mudas de angico-branco.

Outro motivo da falta de resposta das mudas de fedegoso em função da elevação da saturação por bases do Argissolo Vermelho-Amarelo pode estar relacionado ao alto nível de saturação por bases inicial do solo $(39,40 \%)$ e aos baixos teores de $\mathrm{Al}^{3+}\left(0,00 \mathrm{cmol} / \mathrm{dm}^{3}\right)$.

Reis et al. (1997) encontraram resposta negativa à calagem para a produção de matéria seca em mudas de Dalbergia nigra (jacarandá-da-bahia), provavelmente, segundo esses mesmos autores, em razão de se ter Ca suficiente no superfosfato triplo utilizado ou porque, na sua fase juvenil, a exigência de Ca é baixa por essa espécie. Entretanto, Virgens Filho et al. (2001) concluíram que a calagem foi responsável pela maior produção de borracha seca em seringueira.

No Latossolo Vermelho-Amarelo distrófico e no Latossolo Vermelho-Amarelo álico houve diferença significativa para todas as características avaliadas em função da elevação da saturação por bases do substrato, exceto para H no primeiro e para o PMSPA no segundo solo (Tabela 5). Gomes et al. (2004)

Tabela 5 - Resumo da análise de variância dos dados altura (H), diâmetro do coleto (DC), peso de matéria seca da parte aérea (PMSPA), peso de matéria seca das raízes (PMSR) e peso de matéria seca total (PMST) das mudas de fedegoso em resposta à elevação da saturação por bases do substrato, aos 120 dias após a semeadura.

Table 5 - Summary of the analysis of the variation of height $(H)$, stem diameter (DC), dry matter of the aerial part (PMSPA), total root dry matter weight (PMSR) and total dry matter weight (PMST) of the fedegoso seedlings in response of the elevationof the base saturation of the substratum, 120 days after sowing.

\begin{tabular}{|c|c|c|c|c|c|c|c|}
\hline \multirow[t]{2}{*}{ Solo } & \multirow[t]{2}{*}{ FV } & \multirow[t]{2}{*}{ GL } & \multicolumn{5}{|c|}{ Quadrado médio } \\
\hline & & & $\mathrm{H}$ & DC & PMSPA & PMSR & PMST \\
\hline \multirow{4}{*}{$\begin{array}{l}\text { Argissolo vermelho- } \\
\text { amarelo }\end{array}$} & Saturação por bases & 3 & $92,807^{\text {ns }}$ & $3,189^{\mathrm{ns}}$ & $5,137^{\text {ns }}$ & $5,950^{\text {ns }}$ & $19,791^{\mathrm{ns}}$ \\
\hline & Bloco & 3 & $51,307^{\mathrm{ns}}$ & $1,554^{\mathrm{ns}}$ & $1,264^{\mathrm{ns}}$ & $2,531^{\mathrm{ns}}$ & $7,092^{\text {ns }}$ \\
\hline & Resíduo & 9 & 65,710 & 3,274 & 7,468 & 8,269 & 28,624 \\
\hline & CV (\%) & & 30,6 & 22,7 & 35,5 & 36,2 & 33,7 \\
\hline \multirow{4}{*}{$\begin{array}{l}\text { Latossolo vermelho- } \\
\text { amarelo distrófico }\end{array}$} & Saturação por bases & 3 & 20,432 ns & $6,129 *$ & $9,416 *$ & $8,104 *$ & $34,645 *$ \\
\hline & Bloco & 3 & $20,807^{\text {ns }}$ & $1,506^{\mathrm{ns}}$ & $2,765^{\mathrm{ns}}$ & $1,774^{\mathrm{ns}}$ & $8,877^{n s}$ \\
\hline & Resíduo & 9 & 27,960 & 0,419 & 0,915 & 0,482 & 2,195 \\
\hline & CV (\%) & & 35,6 & 11,9 & 26,9 & 24,6 & 23,0 \\
\hline \multirow{4}{*}{$\begin{array}{l}\text { Latossolo vermelho- } \\
\text { amarelo álico }\end{array}$} & Saturação por bases & 3 & $192,944^{*}$ & $13,112 *$ & $42,721^{\mathrm{ns}}$ & $37,757 *$ & $150,547^{*}$ \\
\hline & Bloco & 3 & $6,794^{\mathrm{ns}}$ & $1,861^{\mathrm{ns}}$ & $1,700^{\mathrm{ns}}$ & $3,009^{\mathrm{ns}}$ & $4,990^{\mathrm{ns}}$ \\
\hline & Resíduo & 9 & 21,180 & 2,076 & 11,595 & 4,177 & 27,370 \\
\hline & CV (\%) & & 22,4 & 21,5 & 50 & 39,7 & 43,8 \\
\hline
\end{tabular}

* Significativo a $5 \%$ de probabilidade, pelo teste $\mathrm{F}$.

${ }^{\text {ns }}$ Não significativo a $5 \%$ de probabilidade, pelo teste F. 
observaram resultado diferente em mudas de angicobranco produzidas em Latossolo Vermelho distrófico, onde a matéria seca das raízes não apresentou resposta significativa nos níveis de 24 e $60 \%$ de saturação por bases.

Quando se analisa a relação entre os parâmetros morfológicos, somente a relação entre H/PMSPA e o IQD no Latossolo Vermelho-Amarelo distrófico e a relação H/DC e o IQD no Latossolo VermelhoAmarelo álico, foram significativamente afetadas pela elevação da saturação por bases do substrato (Tabela 6).

No Latossolo Vermelho-Amarelo distrófico, o DC assumiu comportamento linear com os maiores valores ocorrendo próximo à saturação por bases de 70\% (Tabela 3). À medida que se elevou a saturação

Tabela 6 - Resumo da análise de variância dos dados das relações entre altura e diâmetro do coleto (H/DC), altura e peso de matéria seca da parte aérea (H/PMSPA), peso de matéria seca da parte aérea e peso de matéria seca das raízes (PMSPA/PMSR) e do índice de qualidade de Dickson em resposta à elevação da saturação por bases do substrato, aos 120 dias após a semeadura.

Table 6 - Summary of the analysis of the variation between the relation of the height and the stem diameter (H/DC), height and dry matter of the aerial part (H/PMSPA), dry of the aerial part and root dry matter (PMSPA/PMSR) and of the Dickson's quality index in response to the elevation of the base saturation of the substratum, 120 days after sowing.

\begin{tabular}{|c|c|c|c|c|c|c|}
\hline \multirow[t]{2}{*}{ Solo } & \multirow[t]{2}{*}{ FV } & \multirow[t]{2}{*}{ GL } & \multicolumn{4}{|c|}{ Quadrado médio } \\
\hline & & & $\mathrm{H} / \mathrm{DC}$ & H/PMSPA & PMSPA/PMSR & IQD \\
\hline \multirow[t]{4}{*}{ Argissolo vermelho-amarelo } & Saturação por bases & 3 & $0,517^{\mathrm{ns}}$ & $6,269^{\text {ns }}$ & $0,101^{\mathrm{ns}}$ & $0,596^{\mathrm{ns}}$ \\
\hline & Bloco & 3 & $0,822^{\mathrm{ns}}$ & $5,827^{\mathrm{ns}}$ & $0,097^{\mathrm{ns}}$ & $0,454^{\mathrm{ns}}$ \\
\hline & Resíduo & 9 & 0,789 & 10,230 & 0,114 & 2,465 \\
\hline & CV (\%) & & 27,1 & 78,8 & 31,2 & 42,1 \\
\hline \multirow[t]{4}{*}{ Latossolo vermelho-amarelo distrófico } & Saturação por bases & 3 & $2,419^{\mathrm{ns}}$ & $39,816^{*}$ & $0,168^{\text {ns }}$ & $\overline{3,656^{*}}$ \\
\hline & Bloco & 3 & $0,632^{\mathrm{ns}}$ & $8,712^{\mathrm{ns}}$ & $0,059^{\text {ns }}$ & $0,817^{\mathrm{ns}}$ \\
\hline & Resíduo & 9 & 1,592 & 2,757 & 0,103 & 0,325 \\
\hline & CV $(\%)$ & & 43,7 & 31,2 & 23,5 & 32,7 \\
\hline \multirow[t]{4}{*}{ Latossolo vermelho-amarelo álico } & Saturação por bases & 3 & $0,894 *$ & $7,873^{\text {ns }}$ & $2,819^{\mathrm{ns}}$ & $8,610^{*}$ \\
\hline & Bloco & 3 & $0,203^{\mathrm{ns}}$ & $4,528^{\text {ns }}$ & $1,338^{\mathrm{ns}}$ & $1,046^{\mathrm{ns}}$ \\
\hline & Resíduo & 9 & 0,204 & 6,094 & 0,945 & 1,364 \\
\hline & CV (\%) & & 14,7 & 59,3 & 52,3 & 42,4 \\
\hline
\end{tabular}

* Significativo a 5\% de probabilidade, pelo teste $\mathrm{F}$.

${ }^{\text {ns }}$ Não significativo a 5\% de probabilidade, pelo teste F.
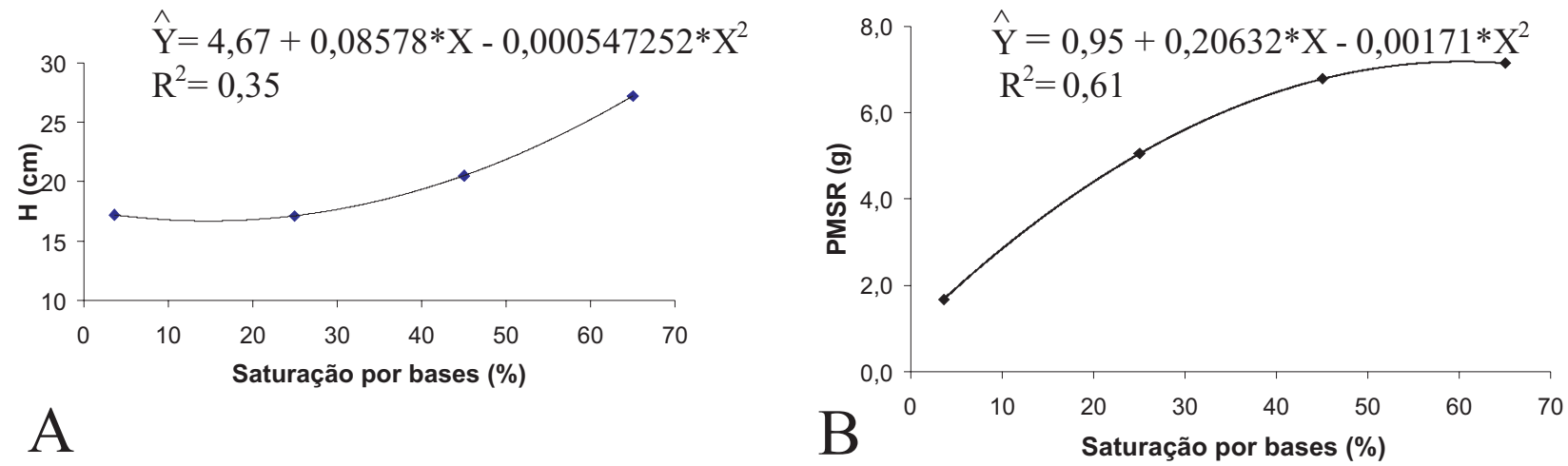

A

Figura 1 - Gráficos da altura (1A) e do peso de matéria seca das raízes (1B) das mudas de fedegoso produzidas em Latossolo Vermelho-Amarelo álico em função da elevação da saturação por bases do substrato aos 120 dias após a semeadura.

Figure 1 - Graphs of the height $(1 \mathrm{~A})$ and the dry matter weight $(1 \mathrm{~B})$ of the fedegoso seedlings produced in red-yellow alic latosoil due to the elevation of the base saturation of the substratum at 120 days after sowing.

R. Árvore, Viçosa-MG, v.34, n.2, p.233-240, 2010 
por bases, houve redução nos valores do quociente entre H/PMSPA, com os menores valores para essa característica próximo à saturação de $60 \%$. Segundo Gomes (2001), essa relação não é, normalmente, utilizada para predizer o padrão de qualidade de mudas, mas pode ser de grande valia para determinar a capacidade de sobrevivência da muda no campo, ou seja, quanto menor o seu valor, maior a possibilidade de sobrevivência. O IQD assumiu comportamento linear com os maiores valores na maior saturação por bases testada (70\%), como pode ser observado na Tabela 4. Portanto, as melhores mudas de fedegoso no Latossolo Vermelho-Amarelo distrófico foram obtidas próximo à saturação de $70 \%$.

No Latossolo Vermelho-Amarelo álico, todas as características afetadas significativamente pela elevação da saturação por bases do substrato obedeceram a um comportamento do tipo quadrático. A H e o PMSR alcançaram os maiores valores próximos à saturação por bases de 65\% (Figuras 1Ae 1B).

Comparando o PMST das mudas de fedegoso produzidas nos três solos, observa-se que no Argissolo Vermelho-Amarelo essa característica não foi influenciada pela elevação da saturação por bases do substrato. No Latossolo Vermelho-Amarelo

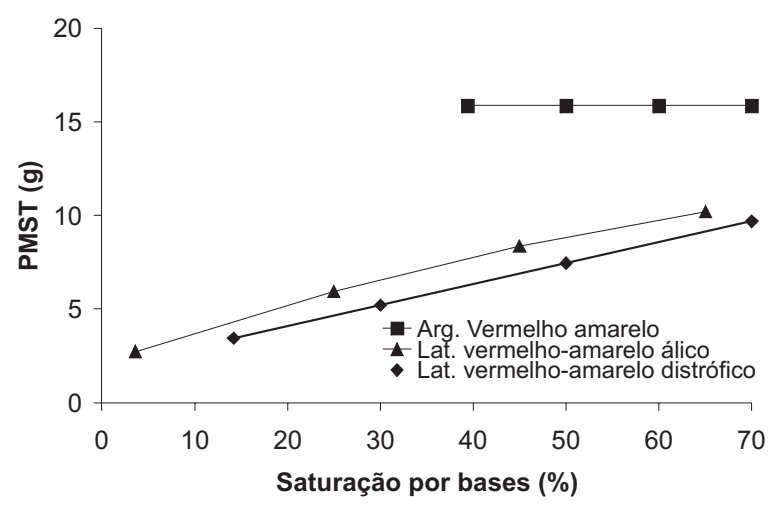

Figura 2 - Peso de matéria seca total das mudas de fedegoso produzidas em três diferentes solos em função da saturação por bases do substrato, aos 120 dias após a semeadura.

Figure 2 - Total dry matter weight of the fedegoso seedlings produced with three different soils due to the base saturation of the substratum at 120 days after sowing.
Tabela 7 - Equações de regressão do peso de matéria seca total das mudas de fedegoso produzidas em três diferentes solos em função da saturação por bases do substrato, aos 120 dias após a semeadura.

Table 7 - Equations of the total dry matter weight of the fedegoso seedlings produced with three different soils due to the base saturation of the substratum at 120 days after sowing.

\begin{tabular}{lc}
\hline Solo & Equação de Regressão \\
\hline $\begin{array}{c}\text { Argissolo Vermelho- } \\
\text { Amarelo }\end{array}$ & $\hat{Y}=\bar{y}$ \\
\hline Latossolo Vermelho- & $\hat{\mathrm{Y}}=1,85+0,11185^{*} \mathrm{X}$ \\
Amarelo distrófico & $\mathrm{R}^{2}=0,68$ \\
\hline Latossolo Vermelho- & $\hat{\mathrm{Y}}=2,13+0,17019 * \mathrm{X}-$ \\
Amarelo álico & $0,00070906 * \mathrm{X}^{2}$ \\
& $\mathrm{R}^{2}=0,53$ \\
\hline
\end{tabular}

* Significativo a 5\% de probabilidade, pelo teste “t”.

distrófico e no Latossolo Vermelho-Amarelo álico, a saturação por bases influenciou, de forma positiva, essa característica, tendo o maior valor ocorrido próximo à máxima saturação testada (65\% no Latossolo Vermelho-Amarelo distrófico e 70\% no Latossolo Vermelho-Amarelo álico), como pode ser observado na Figura 2.

Na Tabela 7 são mostradas as equações de regressão para o PMST das mudas de fedegoso produzidas nos três diferentes solos, onde pôde ser observado o comportamento linear com relação a essa característica no Latossolo Vermelho-Amarelo distrófico e quadrático no Latossolo VermelhoAmarelo álico.

\section{CONCLUSÃO}

Para a produção de mudas de fedegoso, as saturações por bases que forneceram as melhores mudas foram 60\% para o Argissolo Vermelho-Amarelo, 70\% para o Latossolo Vermelho-Amarelo distrófico e 65\% para o Latossolo Vermelho-Amarelo álico.

\section{AGRADECIMENTOS}

À CAPES, pela concessão da bolsa de estudo; ao CNPq, pela bolsa de produtividade em pesquisa; e ao projeto PRODETAB 130-02/01 pelo financiamento deste trabalho.

R. Árvore, Viçosa-MG, v.34, n.2, p.233-240, 2010 


\section{REFERÊNCIAS}

ALVAREZ V., V. H. Equilíbrio de formas disponíveis de fósforo e enxofres em dois latossolos de Minas Gerais. 1974. 125f. Dissertação (Mestrado em Solos e Nutrição de Plantas) - Universidade Federal de Viçosa, Viçosa, MG, 1974.

AMARAL, A. S. et al. Resíduos vegetais na superfície do solo e a eficiência do herbicida Flumet Sulam. Ciência Rural, v.30, n.5, p.789794, 2000.

BARBOSA, Z. et al. Crescimento e composição química foliar de mudas de aroeira (Myracrodon urudeuva Fr.All.Eng) sob diferentes saturações por bases. II teor foliar de micronutrientes. In: CONGRESSO BRASILEIRO DE CIÊNCIA DO SOLO, 25., 1995, Viçosa, MG. Resumos expandidos... Viçosa, MG: SBCS/UFV, 1995. v.2. p.809-810.

BERNARDINO, D. C. S. et al. Crescimento e qualidade de mudas de Anadenanthera macrocarpa (Benth.) Brenan em resposta à saturação por bases do substrato. Revista Árvore, v.29, n.6, p.863-870, 2005.

FAGEIRA, N. K. Efeito da calagem na produção de arroz, milho e soja em solo de cerrado.

Pesquisa Agropecuária Brasileira, v.36, n.11, p.1419-1424, 2001.

FERNANDES, A. R.; CARVALHO, J. G. Crescimento de pupunheira (Bactris gasipaes H.B.K.) em função de relações do K com o Ca e com o Na, em solução nutritiva. Cerne, v.7, n.1, p.84-89, 2001.
FERNÁNDEZ, J. Q. P. et al. Crescimento de mudas de Mimosa tenuiflora submetidas a diferentes níveis de calagem e doses de fósforo, potássio e enxofre. Revista Árvore, v.20, n.4, p.425-431,1996.

GARCIA, N. C. P. Efeitos da calagem e de níveis de fósforo sobre o crescimento e composição mineral da mudas de cedro (Cedrela fissilis Vell.). 1986. 40f. Dissertação (Mestrado em Ciência Florestal)Universidade Federal de Viçosa, Viçosa, MG, 1986.

GOMES, K. C. O. et al. Influência da saturação por bases no crescimento de mudas de angico branco. Revista Árvore, v.28, n.6, p.785-792, 2004.

GOMES, J. M. Parâmetros morfológicos na avaliação da qualidade de mudas de Eucalyptus grandis, produzidas em diferentes tamanhos de tubete e dosagens de N-P-K. 2001. 166f. Tese (Doutorado em Ciência Florestal) - Universidade Federal de Viçosa, Viçosa, MG, 2001.

LORENZI, H. Árvores brasileiras. Nova Odessa: Plantarum, 1992. 352p.

PASSOS, M. A. A. Efeito da calagem e de fósforo no crescimento inicial da algaroba (Prosopis juliflora (SW) DC). 1994. 57f. Tese (Doutorado em Fitotecnia) Universidade Federal de Viçosa, Viçosa, MG, 1994.

REIS, M. G. F. et al. Exigências nutricionais de mudas de Dalbergia nigra (Vell.) Fr. Allem (Jacarandá-daBahia) produzidas em dois níveis de sombreamento. Revista Árvore, v.21, n.4, p.463-471, 1997.

VIRGENS FILHO, A. C.; MOREIRA, A.; CAMRGO E CASTRO, P. R. Efeito da calagem e adubação da seringueira no estado nutricional e produção de borracha seca. Pesquisa Agropecuária Brasileira, v.36, n.8, p.1019-1026, 2001. 